\title{
Number of Para-aortic Lymph Nodes Positive for Tumor by H\&E
}

National Cancer Institute

\section{Source}

National Cancer Institute. Number of Para-aortic Lymph Nodes Positive for Tumor by

H\&E. NCI Thesaurus. Code C158645.

A request to specify the number of para-aortic lymph nodes found positive for tumor by $H \& E$. 